Dhaka Univ. J. Biol. Sci. 24(1): 73-81, 2015 (January)

\title{
DEVELOPMENTAL STAGES OF A COMMON GRASS YELLOW BUTTERFLY, EUREMA HECABE
}

\author{
M. Hasina Arju, Md. Kowser Miah, Nousheen Parven and M.A. Bashar \\ Environmental Biology and Biodiversity Laboratory, Department of Zoology, \\ University of Dhaka, Dhaka-1000,Bangladesh
}

Key words: Developmental stage, Eurema hecabe, Life cycle, Larval instars

\begin{abstract}
Developmental stages of pierid butterfly (Lepidoptera: Pieridae) Eurema hecabe, duration and survival rate of developmental stages was studied in laboratory condition under $29 \pm 3^{\circ} \mathrm{C}$ temperature with $\mathrm{RH} 78 \pm 2 \%$. Egg, five larval instars and pupal stage were distinct. The average duration from egg to adult, incubation period, larval and pupal period was recorded $22.0 \pm 0.7,5.7 \pm 6$, $10.5 \pm 0.4$ and $6.5 \pm 0.4$ days, respectively. Twenty seven out of 34 larvae were successfully completed their whole 5 instars. Positive correlation among the larval instars, amount of food consumption and excretion of faeces were observed. About $65 \%$ pupae emerged as adult at laboratory condition.
\end{abstract}

\section{Introduction}

A successful and effective conservation management of butterflies depends on sound knowledge of their life history and host plant requirements in the wild state. Butterflies are particularly sensitive to environmental variations ${ }^{(1)}$. Positive relations have been found between butterflies diversity with its host plant diversity, habitat complexity, landscape structure, topographic and moisture gradients and climate(2-10). Various sensory cues are essential for insects to locate and reach the host plants properly and then perform the appropriate behaviour(11). Insects recognize the species and the quality of a plant to decide what behaviour they should perform ${ }^{(12-13)}$. Butterflies are very much related with their host plants(14). Pieridae is the third largest butterfly family of the world with 2000 described species(15). Seven families of butterflies, such as Papilionidae, Pieridae, Nymphalidae, Danaidae, Satyridae, Lycaenidae and Hesperiidae are found in Bangladesh. Among the seven families only Pieridae and Nymphalidae have been taxified and identified up to species level on the basis of wing-venation in Bangladesh(16-18). Various behavioural aspects, such as foraging, resting, flying, mating and egg laying of Pierid butterflies is associated with plants ${ }^{(19)}$. Pierids utilize various plant species under the family Leguminasae for maintaining their developmental stages $^{(20)}$.

The present work has been aimed primarily to examine the life cycle, identification of their developmental stages and constraint factors to complete the developmental stages. 
With a view to studying the biology with characteristic behavioural activities in laboratory for considering the role of Pierid butterfly in the conservation of forest ecosystem.

\section{Materials and Methods}

The study was conducted in the Environmental Biology and Biodiversity Laboratory (EBBL), Department of Zoology, University of Dhaka and in the Germplasm Centre (GPC) of Zoological Garden from May to November, 2009. Eurema hecabe lays eggs on Cassia fistula, C. alata, C. auriculata, C. tora, Pithecellobium dulce etc. During the experiment eggs were collected from Pithecellobium dulce leaves at the Curzon Hall campus of the University of Dhaka. Eggs on host plant were recorded according to the method of Kunte $^{(21)}$. The eggs were collectively connected with the leaves of host plant, which were collected by cutting the host plant stems at $45^{\circ}$ angle. Immediately after cutting it was wrapped with soaked cotton. Water was sprayed as and when necessary, then the stem was placed onto the larvae-rearing cage. Larvae were reared in 3-layered plastic cages. The length, width and height of the 1st layer were $362.5,300$ and $150 \mathrm{~mm}$, respectively; the 2nd layer were 350, 287.5 and $125 \mathrm{~mm}$, respectively and the 3rd layer were 350, 287.5 and $62.5 \mathrm{~mm}$, respectively. Two pieces of cork-sheet were fixed to provide space between 1st and 2nd layers. The 2nd layer was perforated to pass air and maintain proper humidity. The 3rd layer was the cover of the cage. The room temperature was $29 \pm 3^{\circ} \mathrm{C}$ with $\mathrm{RH} 78 \pm 2 \%$. The eggs were observed following the methods used by Bashar et al.(22).

Larvae were kept in the same rearing cages. The larvae of different instars were measured by using a millimeter scale. Fresh leaves of host plant were supplied as food regularly to larvae. After providing fresh leaves larvae were replaced and the old foliage was removed. Larvae were observed regularly for supplying food, collecting faeces and to identify the molting and mortality rate. A hairy soft brush was used to clean cages and maintain a proper environment for larval rearing and avoiding unhygienic condition. The larval instar was recorded between the time of larval first - appearance and the larval first - moult to the next instar with changes of morphological characteristics such as measurement of body size, changement of body colouration, feeding quantity etc. Larvae were reared by following the method of Zalucki et al.(23) and their feeding potential was measured according to the method used by Singh ${ }^{(24)}$. The amount of food consumption and faeces (gm) were recorded by using Precision Electronic Balances following the method of Barua and Slowik ${ }^{(19)}$.

Pupae with rearing cage were kept in the adult emergence cabinet. It was rectangular in shape with $525 \mathrm{~mm}$ length, $450 \mathrm{~mm}$ wide and $900 \mathrm{~mm}$ in height and made with iron rods. The cabinet was covered by the muslin net to prevent the butterfly dispersion or flight when the adult emerged from the pupa. There were $8-10$ holes per $1 \mathrm{~cm}^{2}$ area in

net for maintaining the proper light and aeration. A zipper was attached to the muslin 
net for entry and exit of the pupal cage to observe. Damp sponges were kept in the emergence cabinet at the period of adult emerge for providing sufficient humidity. The pupal stages of the butterfly were studied following the method of Baker(25). The biology of butterfly was studied according to Alam et al.(26), Rao et al. (27) and Hill(28).

\section{Results and Discussion}

The different developmental stages, viz. egg, larva, pupa and adult of E. hecabe are presented in Fig. 1.

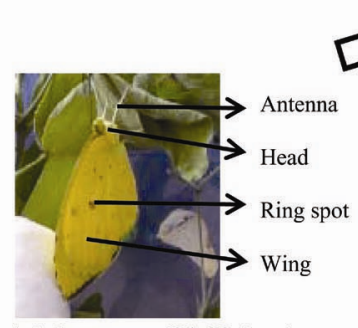

h) Adult emerge (21-23 days)
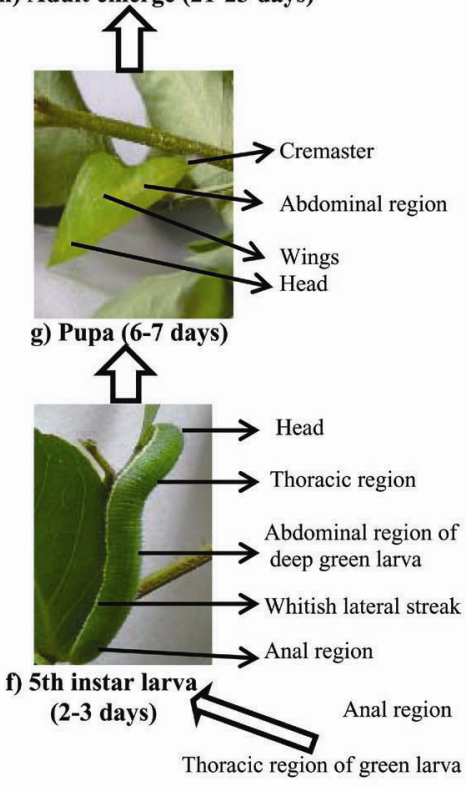

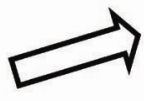$$
\text { (1) }
$$

\section{(5-7days)}

a) Egg on young leaf

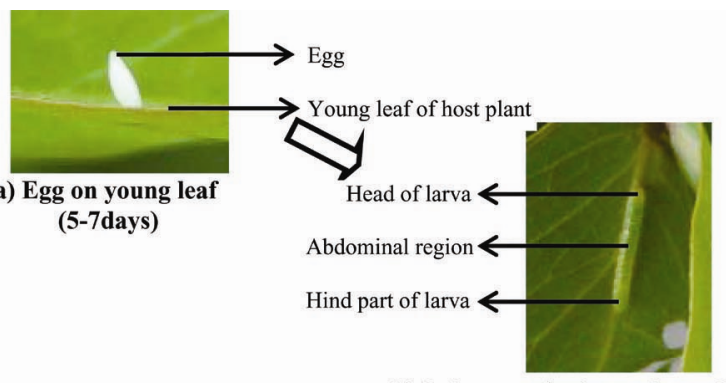

b) Pale green 1st instar larva (2-3 days)

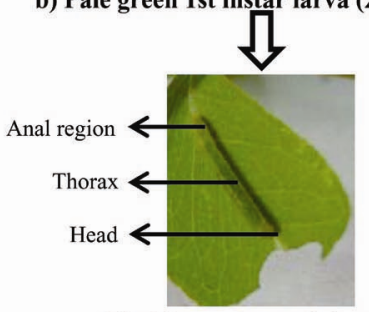

c) 2nd instar larva (2-3 days)

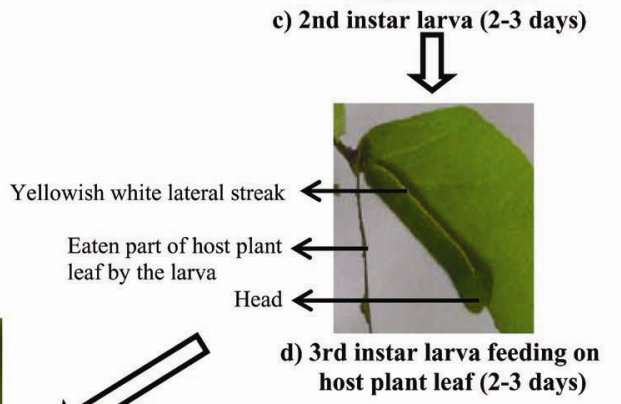

Head

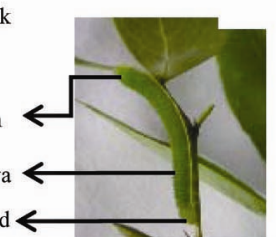
host plant leaf (2-3 days)

Fig. 1. Developmental stages of Eurema hecabe.

Eggs were erect and cylindrical in shape and measuring about $2 \mathrm{~mm}$ in height and 1 $\mathrm{mm}$ in diameter at the broadest region. Eggs consist of a hard ridged outer layer of shell, called the chorion. A thin coating of wax present in chorion which prevents eggs from drying out. 
Incubation period of $E$. hecabe was studied in laboratory at $29 \pm 3^{\circ} \mathrm{C}$ temperature with $\mathrm{RH} 78 \% \pm 2$. The colour of egg was found white immediately after laying, which became creamy white within a day. It became dark white at the time of hatching. The fully formed embryo was clearly visible within the transparent egg shell during just before hatching. By splitting the transparent egg shell longitudinally, the young larva gnaws and came out.

No larvae were recorded to hatch before passing five days and after Seven days as incubation period. About 34 eggs (20\%) were found to hatch on 5th day, $18 \%$ on 5.5th day, $29 \%$ on 6 th day, $24 \%$ were 6.5 th day and $9 \%$ were 7 th day. Maximum duration was 7 days with minimum of 5 . The average period was $5.7 \pm 0.6$ days (Fig. 2 ).

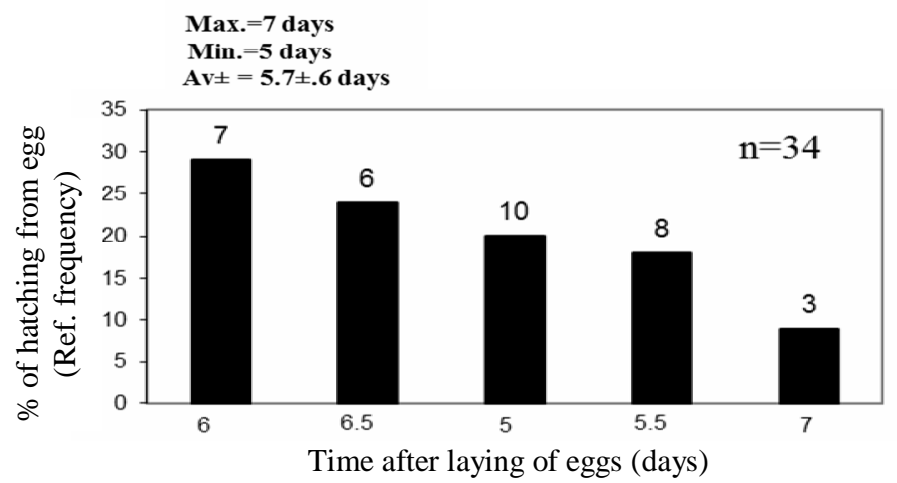

Fig. 2. Rate of incubation period of Eurema hecabe in laboratory condition.

The newly hatched larva feed on its own egg shell first. It grows through a series of moults and each intermediate stage is called an instar. The larva of E. hecabe moult usually four times. So, first, second, third, fourth and fifth larval instars were recorded. During the time of moulting the larva stop feeding and take rest.

First instar larvae (Fig. 1b) were very tiny. Body shapes were cylindrical and pale green in colour. Average duration was $2.3 \pm 0.5$ days. The maximum length and width of the larvae were 7 and $2 \mathrm{~mm}$, respectively (Table 1). Body segments were poorly visible by necked eye. Head was rounded and plain. As larvae at this instar were very tiny, it consumed small amount of young host-leaf. Atluri et al. ${ }^{(29)}$ reported that the duration of first instar larva in Catopsilia pyranthe was 2 - 3 days and body length was 4.5 - 5.5 (5.0 \pm $0.2) \mathrm{mm}$.

Second instar larvae (Fig. 1c) were pale green in colour. Lateral sides, head and anal regions were yellowish. Body segments were slightly visible. Average duration was $2.3 \pm$ 0.5 days. The maximum length and width of the larvae were 12 and $3 \mathrm{~mm}$, respectively (Table 1). It consumed small amount of food and excreted less amount of black faeces. 
Arju et al. (30) observed that the body of Catopsilia pyranthe at second inster was pale green, lateral sides were yellow with pale yellow head and the duration was 2-3 days while the body length was 9-17 $\mathrm{mm}$.

Body of the third instar larvae (Fig. 1d) was rough, hairless with yellowish white lateral streak. Legs and prolegs were distinct. Average duration was $2.3 \pm 0.5$ days. The average length and width was $18 \pm 0.6$ and $4 \pm 0.6 \mathrm{~mm}$. respectively (Table 1 ). In this stage larvae fed very fast and grew rapidly. It excreted a huge amount of faeces which was black in colour and granular. Arju et al. (30) examined before that the duration of $3^{\text {rd }}$ instar larva of Catopsilia pyranthe was 2-3 days and body length was $18-28 \mathrm{~mm}$.

Body of the fourth instar larvae (Fig. 1e) was green in colour and head was rounded with yellowish green. Average duration was $2.3 \pm 0.5$ days. The larvae attained maximum $24 \mathrm{~mm}$ length and $6 \mathrm{~mm}$ width (Table 1). At this developmental stage larvae consume host plant leaves voraciously. Alam et al.(26) reported that the body colour of pierid larvae was green and the lateral sides were yellow, the duration of instar period was 2 - 3 days and body length was $19.0-20.5 \mathrm{~mm}$.

Table 1. Morphometric analysis of larvae and pupae of Eurema hecabe.

\begin{tabular}{|c|c|c|c|c|}
\hline \multirow{2}{*}{$\begin{array}{c}\text { Stages } \\
\text { (larvae } \\
\text { and } \\
\text { pupae) }\end{array}$} & \multicolumn{2}{|c|}{ Measurement of body size } & \multirow{2}{*}{$\begin{array}{c}\text { Duration of the } \\
\text { developmental } \\
\text { stage (days) }\end{array}$} & \multirow{2}{*}{$\begin{array}{l}\text { Morphological characteristics of } \\
\text { larval instars and pupae }\end{array}$} \\
\hline & Length $(\mathrm{mm})$ & Width (mm) & & \\
\hline \multirow[t]{3}{*}{ 1st instar } & Min. 3 & Min. 1.5 & Min. 2 & - Cylindrical body \\
\hline & Max. 7 & Max. 2 & Max. 3 & - Pale green in colour \\
\hline & Av. $\pm=6.3 \pm 0.6$ & Av. $\pm=1.50 \pm 0.5$ & Av. $\pm=2.3 \pm 0.5$ & - Rounded, yellowish head \\
\hline \multirow[t]{3}{*}{ 2nd " } & Min. 8 & Min. 2.5 & Min. 2 & - Pale green in colour \\
\hline & Max. 12 & Max. 3 & Max. 3 & - Lateral sides, head and anal \\
\hline & Av. $\pm=11.4 \pm 0.7$ & Av. $\pm=2.75 \pm 0.6$ & Av. $\pm=2.3 \pm 0.5$ & regions yellowish \\
\hline \multirow[t]{3}{*}{ 3rd " } & Min. 13 & Min. 3.5 & Min. 2 & - Green in colour \\
\hline & Max. 19 & Max. 4.5 & Max. 3 & - Yellowish white lateral streak \\
\hline & Av. $\pm=18 \pm 0.6$ & Av. $\pm=4 \pm 0.6$ & Av. $\pm=2.3 \pm 0.5$ & present \\
\hline \multirow[t]{3}{*}{4 th " } & Min. 20 & Min. 5 & Min. 2 & - Green in colour \\
\hline & Max. 24 & Max. 6 & Max. 3 & - Head rounded, yellowish green \\
\hline & Av. $\pm=23 \pm 0.7$ & Av. $\pm=5.50 \pm 0.7$ & Av. $\pm=2.3 \pm 0.5$ & \\
\hline \multirow[t]{3}{*}{5 th " } & Min. 25 & Min. 6.5 & Min. 2 & - Deep green in colour \\
\hline & Max. 29 & Max. 8 & Max. 3 & - Body segments very distinct \\
\hline & Av. $\pm=26.9 \pm 1.4$ & Av. $\pm=7.25 \pm 0.8$ & Av. $\pm=2.2 \pm 0.4$ & - True legs and prolegs visible \\
\hline \multirow[t]{3}{*}{ Pre-pupa } & Min. 19 & Min. 5.5 & Min. 1 & - dull shade of pale green in colour \\
\hline & Max. 23 & Max. 6 & Max. 1.5 & - slowly beings to shrink its body \\
\hline & Av. $\pm=21 \pm 0.7$ & Av. $\pm=5.75 \pm 0.8$ & Av. $\pm=1.25 \pm 0.6$ & \\
\hline \multirow[t]{3}{*}{ Pupa } & Min. 18 & Min. 8 & Min. 6 & - green in colour \\
\hline & Max. 20 & Max. 10 & $\operatorname{Max}=7$ & - wing-cases united to form a deep \\
\hline & Av. $\pm=19 \pm 0.6$ & Av. $\pm=9 \pm 0.6$ & Av. $\pm=6.5 \pm 0.44$ & sharp keel \\
\hline
\end{tabular}

Body colour of the fifth instar larvae (Fig. 1f) colour was deep green. Ten abdominal and three thoracic segments were very distinct. In each segment a pair of true legs was 
distinct. Anal prolegs were observed at the last segment. Average duration was $2.2 \pm 0.4$ days. The maximum length and width of the larvae were 29 and $8 \mathrm{~mm}$ respectively (Table 1). At this stage larvae also consumed leaves as their food voraciously and excreted a huge amount of faeces.

Fig. 3 shows the total duration of larval period. No larvae were recorded to turn into pupa before passing 10 days and after 11 days. About 27 larvae (48\%) were found to turn into pupa on 10 days, $30 \%$ on 11 days and $22 \%$ on 10.5 day. Maximum duration was recorded 11 days and minimum was 10 days.

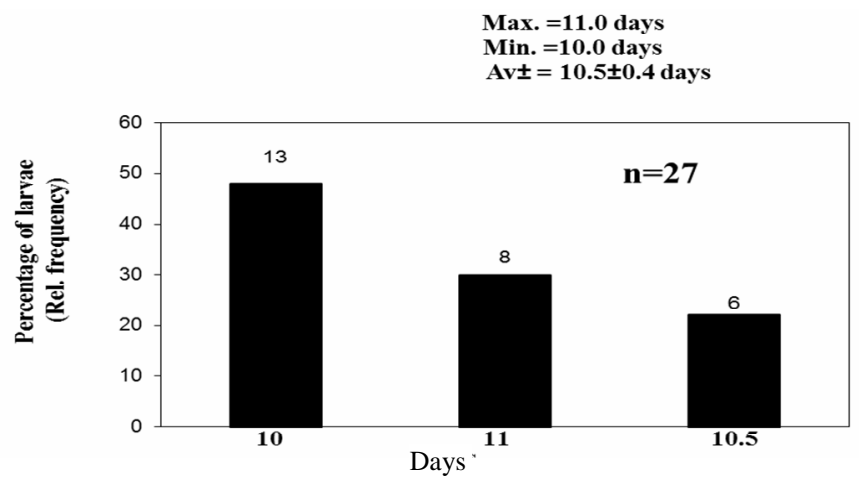

Fig. 3. Total duration of larval period of Eurema hecabe in laboratory condition.

In the final developmental stages of the larvae the length and width were measured 19-23 and 5.5-6 mm, respectively (Table 1). Body colour changed to a dull shade of pale green. The larvae were gradually shrinked. The larvae ceased eating and wandered around for searching a pupation site. At the chosen site, the larvae settled itself for pupation by spinning a silk girdle.

The pupal stage (Fig. 1g) and pupation period started after one day of the pre-pupal stage. Average duration of pupae were recorded to emerge as adult on $6.5 \pm 0.44$ days. The length and width was measured $18-20$ and $8-10 \mathrm{~mm}$, respectively (Table 1). It was green in colour. The abdominal segments were round but the thorax was much compressed. The wing-cases united to form a deep sharp keel. The head-case terminated in a short pointed snout.

Eurema hecabe emerge (Fig. 1h) from the pupa by splitting the pupal cage. After the emergence, the crumpled wings of the adult get expanded and smoothened out due to the pressure of the blood.

During the study of E. hecabe in laboratory the total duration from egg to adult emerge was recorded 21 to 23 days. According to Arju et al.(30) the average duration from egg to adult, larval and pupal stage of a mottled emigrant butterfly (Catopsila pyranthe) were 23.87, 10.93 and 6.62 days, respectively. 
There was a positive correlation between the number of larval instar and the amount of food consumption. The maximum food consumption was recorded $2.12 \mathrm{gm}$ in fifth instar and minimum was $0.10 \mathrm{gm}$ in first instar (Fig. 4).

There was also a positive correlation among the larval instar and the amount of excreted faeces. The highest amount of faeces was recorded $0.063 \mathrm{gm}$ in fifth instar and lowest was 0.0029 gm in first instar (Fig. 5).

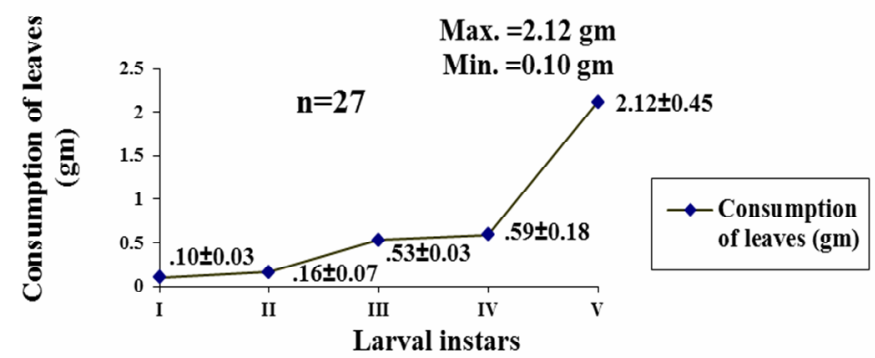

Fig. 3. Consumption of host plant leaves by each larval instar of Eurema hecabe.

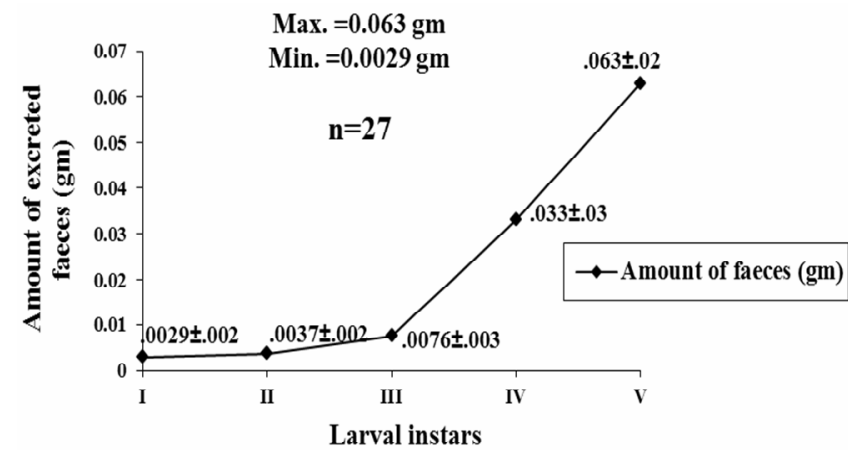

Fig. 4. Amount of excreted faeces after each larval moulting of Eurema hecabe.

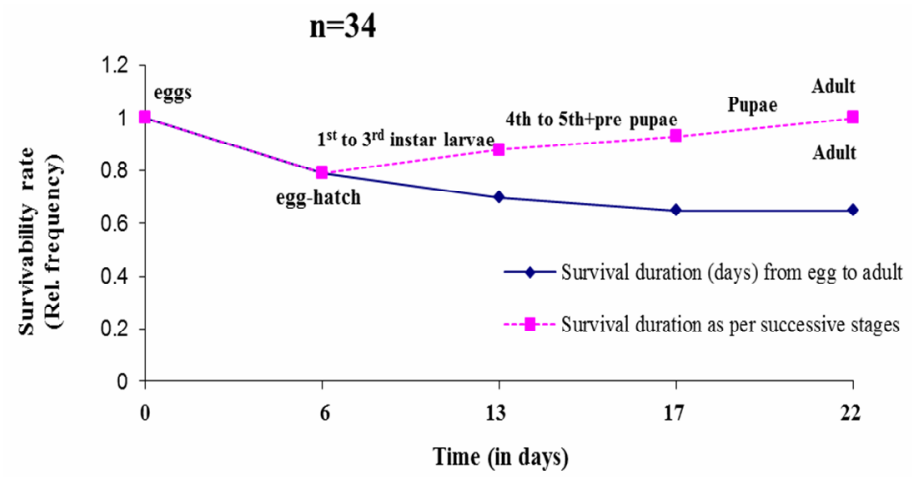

Fig. 5. Survivability of Eurema hecabe in different developmental stages. 
The total survival rate from egg to adult was recorded (65\%). Among 34 individuals survival rate of egg was recorded $79 \%$ (27 eggs). Survival rate of larva was recorded $82 \%$ (22 out of 27 larvae). Out of 22 fifth instar-stage larvae all of them successfully came out to the adult. In this case survival rate of pupa was $100 \%$. So, survival rate was highest in pupal stage and it was lowest in egg-hatch (Fig. 6).

Butterflies are very discriminating in selection of their host plants. The selection of host plants and the trophic relation with them for life maintenance are very specific. This specificity establishes a bonding for maintenance and sustenance of life style and life cycle in butterflies with phenology of host plants. On the other hand, these plants are dependent on the butterflies for their pollination purposes and gene-flow activities.

\section{References}

1. Scoble MJ 1992. The Lepidoptera: Form, Function and Diversity. Oxford University Press, New York. pp. 253.

2. Erhardt A. 1985. Diurnal Lepidoptera: Sensitive indicators of cultivated and abandoned grassland. J. Appl. Ecol. 22: 849-861.

3. Thomas CD and HC Malorie 1985. Rarity, species richness and conservation: Butterflies of the atlas mountains in Morocco. Biological Conservation 33: 95-117.

4. Leps J and K Spitzer 1990. Ecological determinants of butterfly communities (Lepidoptera, Papilionidae) in the Tam Dao Mountains, Vietnam. Acta Entomologica Bohemoslovaca 87: 182-194.

5. Spitzer K, J Jaros, J Havelka and J Leps 1997. Effect of small-scale disturbance on butterfly communities of an Indochinese mountain rainforest. Biological Conservation 80: 9-15.

6. Molina JM and JM Palma 1996. Butterfly diversity and rarity within selected habitats of western Andalusia, Spain (Lepidoptera: Papilionoidea and Hesperiodea). Nota Lepidopterologica 78: 267-280.

7. Wood PA and MJ Samways 1992. Landscape element pattern and continuity of butterfly flight paths in an ecologically landscaped botanic garden, Natal, South Africa. Biological Conservation 58: 149-166.

8. Kremen C 1992. Assessing the indicator properties of species assemblages for natural areas monitoring. Ecological Applications 2: 203-217.

9. Pollard E and TJ Yates 1993. Monitoring Butterflies for Ecology and Conservation. Chapman and Hall. London. pp. 443.

10. Parmesan C 1996. Climate and species range. Nature 382: 765-766.

11. Bernays EA and RF Chapman 1994. Host-Plant Selection by Phytophagous Insects. Chapman and Hall. New York, USA.

12. Prokopy RJ, RH Collier and S Finch 1983. Visual detection of host plant by cabbage root flies. Ento. E. Applicata. 34: 85-89.

13. Renwick JAA and FS Chew 1994. Oviposition behavior in Lepidoptera. Annual Review of Entomology 39: 377-400. 
14. Robbins RK and PA Opler 1997. Butterfly diversity and a preliminary comparison with bird and mammal diversity. Joseph Henry Press, Washington D.C. pp. 69-82.

15. Fres PS 1989. The Illustrated Encyclopedia of the Butterfly World. Salamander Books Ltd. pp.1-275.

16. Bashar MA, MA Mamun and SKM Rahaman 2005. Wing-venation as a factor for the identification of Pierid butterflies in the forests of Bangladesh. Bangladesh J. Zool. 33(1): 49-56.

17. Bashar MA, MA Mamun, AFM Aslam and AK Chowdhury 2006a. Biodiversity maintenance and conservation of Butterfly-Plant Association in some forests of Bangladesh. Bangladesh J. Zool. 34(1): 55-67.

18. Bashar MA, MA Mamun, HR Khan and AK Chowdhury 2006b. Wing-venation as a factor for the identification of Nymphalid butterflies in the forests of Chittagong and Cox's Bazar (Bangladesh). Bangladesh J. Zool. 34(2):187-193.

19. Barua KK and J Slowik 2007. Study on the biology and consumption potential of common rose, Pachliopta aristolochiae (Lepidioptera: Papilionidae) on Aristolochia tagala. Polish J. Ent. 76(4): 341-352.

20. Boggs CL 1987. Ecology of nectar and pollen feeding in Lepidoptera. Nutritional Ecology of Insects, Mites, Spiders and Related Invertebrates. Wiley, New York. 369 - 391.

21. Kunte K 2006. Addition to known larval host plants of Indian Butterfly. J. Bombay Nat. Hist. Soc.103 (1): 119-120.

22. Bashar MA, N Parveen and MAK Chowdhury 2008. Case-making insect pest (Sinclita occidentalis: Pyralidae) and its characteristics association with duckweeds in minipond ecosystem. Dhaka Univ. J. Biol. Sci. 17(2): 109-118.

23. Zalucki MP, AR Clarke and SB Malcolm 2002. Ecology and behavior of first instar larval Lepidoptera. Annual Review of Entomology 47: 361-393.

24. Singh I and G Singh 1993. Assessment of foliage loss caused by different larval instars of Bihar hairy caterpillar, Spilosoma obliqua (Walker) on sunflower. J. Insect. Sci. 6(2): 185-186.

25. Baker RR 1984. The Biology of Butterflies. Royal Entomological Society of London. Academic Press, London, UK. pp. 279-296.

26. Alam MM, MA Bashar and HR Khan 2014. Biology of common rose butterfly Pachliopta aristolochiae Fabricius (Lepidoptera : Papilionidae) on the host plant, Aristolochia indica L. (Aristolochiaceae). Dhaka Univ. J. Biol. Sci. 23(2): 109-117.

27. Rao ARK, TM Krishna, SVRK Rao, BC Reddy, KH Babu and LK Gopal 2006. Studies on morphometrics and biology of citrus butterfly Papiliodemoleus Linnaeus (Lepidoptera: Papilionidae) on acid lime, Citrus aurantifolia Swingle. Entomon. 515: 630-640.

28. Hill CJ 1989. 1. The effect of adult diet on the biology of butterflies. 2. The common crow butterfly, Euploea corecorinna. Oecologia 81: 258-266.

29. Atluri JB, SPV Ramana and CS Reddi 2004. Ecobiology of the tropical pierid butterfly Catopsilia pyranthe. C. Sci. 86(3): 457-461.

30. Arju MH, MA Bashar and G Moula 2010. Developmental stages of mottled emigrant butterfly Catopsilia pyranthe. Dhaka Univ. J. Biol. Sci. 19(2):171-179. 